Neumann, M., Bensing, J., Wirtz, M., Wubker, A., Scheffer, C., Tauschel, D., Edelhauser, F., Ernstmann, N., Pfaff, H. The impact of financial incentives on physician empathy: a study from the perspective of patients with private and statutory health insurance. Patient Education and Counseling: 2011, 84(2), 208-216

\begin{tabular}{|l|l|}
\hline $\begin{array}{l}\text { Postprint } \\
\text { Version }\end{array}$ & 1.0 \\
\hline Journal website & $\underline{\mathrm{http} / / / \mathrm{dx} . \text { doi.org/10.1016/j.pec.2010.07.012 }}$ \\
\hline Pubmed link & $\underline{\mathrm{http} / / / \text { www.ncbi.nlm.nih.gov/pubmed/20708897 }}$ \\
\hline DOI & $10.1016 /$ j.pec.2010.07.012 \\
\hline
\end{tabular}

This is a NIVEL certified Post Print, more info at http://www.nivel.eu

\title{
The impact of financial incentives on physician empathy: A study from the perspective of patients with private and statutory health insurance ${ }^{\text {th }}$
}

\author{
MELANiE NeUmanN ${ }^{\mathrm{A}, \mathrm{B}, \mathrm{C},}$, JOZIEN BENSING ${ }^{\mathrm{D}, \mathrm{E}}$, MARKUS WIRTZ $^{\mathrm{F}}$, ANSGAR WÜBKERG, \\ CHRISTIAN SCHEFFER $^{\mathrm{A}, \mathrm{C}, \mathrm{H}}$, DIETHARD TAUSCHEL ${ }^{\mathrm{A}, \mathrm{H}}$, FRIEDRICH EDELHÄUSER $^{\mathrm{A}, \mathrm{H}}$, NICOLE \\ ERNSTMANN $^{\mathrm{B}}$ AND HOLGER PFAFF ${ }^{\mathrm{B}}$ \\ ${ }^{a}$ Gerhard Kienle Chair for Medical Theory, Integrative and Anthroposophic Medicine; \\ Integrated Curriculum for Anthroposophic Medicine (ICURAM), Faculty for Health, Private \\ University of Witten/Herdecke, Germany \\ ${ }^{b}$ Institute for Medical Sociology, Health Services Research and Rehabilitation Sciences, \\ Department of Human Sciences and Department of Medicine, University of Cologne, \\ Germany \\ ${ }^{c}$ Interdisciplinary Center for Health Services Research, Faculty for Health, Private University \\ of Witten/Herdecke, Germany \\ ${ }^{\mathrm{d}}$ NIVEL, Netherlands Institute for Health Services Research, Utrecht, The Netherlands \\ e Utrecht University, Department of Health Psychology, Utrecht, The Netherlands \\ ${ }^{f}$ Institute for Psychology, University of Education Freiburg, Germany \\ ${ }^{9}$ Department of Institutional Economics and Health Systems Management, Private \\ University of Witten/Herdecke, Germany \\ ${ }^{\mathrm{h}}$ Clinical Education Ward for Integrative Medicine (CEWIM), Medical Department, Private \\ University of Witten/Herdecke, Germany
}

\begin{abstract}
Objective We hypothesized that patients' ratings of physician empathy (PE) would be higher among those with private health insurance (PHI, referring to financial incentive) than among patients with statutory health insurance (SHI).

Methods A postal survey was administered to 710 cancer patients. PE was assessed using the Consultation-and-Relational-Empathy measure. T-tests were conducted to analyse whether PHI and SHI-patients differ in their ratings of PE and variables relating to contact time with the physician. Structural-equationmodelling (SEM) verified mediating effects.

Results PHI-patients rated physician empathy higher. SEM revealed that PHIstatus has a strong significant effect on frequency of talking with the physician, which has a strong significant effect (1) on PE and (2) has a moderate effect on patients' perception of medical staff stress, thereby also affecting patients' ratings of $\mathrm{PE}$.
\end{abstract}


Neumann, M., Bensing, J., Wirtz, M., Wubker, A., Scheffer, C., Tauschel, D., Edelhauser, F., Ernstmann, N., Pfaff, H. The impact of financial incentives on physician empathy: a study from the perspective of patients with private and statutory health insurance. Patient Education and Counseling: 2011, 84(2), 208-216

Conclusions Our findings suggest that PHI-status is one necessary precondition for physicians spending more time with the patient. Spending more time with the PHI-patient has two major effects: it results in a more positive perception of PE and positively impacts PHI-patients' perception of medical staff stress, which in turn, again influences PE.

Practical implications Health policy should discuss these findings in terms of equality in receiving high-quality care.

\section{INTRODUCTION}

One essential prerequisite for successful patient-centred consultation [1] in clinical settings is the physician's empathy [2], [3], [4], [5], [6], [7], [8], [9], [10] and [11]. One definition of physician empathy is the "socio-emotional competence of a physician to be able to understand the patient's situation, perspective and feelings, to communicate that understanding and check its accuracy, and to act on that understanding with the patient in a helpful (therapeutic) way" [12, p. S1].

Although physician empathy is assumed to improve physical [13] and psychosocial health outcomes [9], [10] and [11], little is known about how to motivate physicians to be empathic [11]. As financial incentives are a fundamental staff motivator [14] and [15], we aim to explore their contribution in clinical settings; namely, whether financial incentives can modify physicians' empathic behaviour. Financial incentives referred to treating patients with private health insurance (abbreviated as PHI; equivalent to "fee-for-service"), as physicians can charge more for benefits and/or higher fees in PHI than in statutory health insurance (abbreviated as SHI, equivalent to "capitation") (compare Section 1.3).

Hence, the aim of this inquiry was to study the influence of health insurance type on physicians' empathic behaviour from the patients' perspective; in particular, if variables relating to contact time with the physician might play a mediating role in this relationship.

\subsection{Theoretical background}

The theoretical background of our inquiry draws closely on the "Conceptual framework of influences on health worker motivation" developed by Franco et al. [15] (see Fig. 1). In their in-depth research into health worker motivation [15] and [16] they assumed that work motivation is not an individual or organisational attribute, but results from the interaction between individuals and their work environment. Thus, local organisational and broader sector policies can potentially affect health workers' motivation, either positively or negatively [16]. Consequently, we can assume a relationship between current health policies and health worker motivation. Namely, provider payment mechanisms (e.g. PHI or SHI) can have intended and unintended effects on health worker motivation [15] and [16].

\section{[FIGURE 1]}

Moreover, economic theory and common sense both suggest that payment methods can affect people's working patterns [17] and [18].

\subsection{Empirical background}

Empirical background for this study is previous research, which found that patients are more satisfied with healthcare in private practice [19], [20], [21], [22], [23] and [24]. Further, PHI-patients' perceptions of their relationship and communication with physicians were better than SHI-patients [25], [26] and [27]. Likewise, Kao et al. [28] showed that patients reported greater trust in their physician in private health plans. Sturm et al. [29] showed that patients with current depressive disorders in prepaid plans switched providers or 
Neumann, M., Bensing, J., Wirtz, M., Wubker, A., Scheffer, C., Tauschel, D., Edelhauser, F., Ernstmann, N., Pfaff, H. The impact of financial incentives on physician empathy: a study from the perspective of patients with private and statutory health insurance. Patient Education and Counseling: 2011, 84(2), 208-216

ended relationships with their providers significantly earlier than patients in fee-for-service plans.

Conversely, a Dutch study comparing fee-for-service with fixed salary plans found that ive physicians on fixed salaries provided longer visits, more information and advice, and greater empathy [30]. Gosden et al. [31] also showed salary payment to be associated with longer consultations and more preventive care. However, fee-for-service resulted in greater continuity of care [31] and [32].

\subsection{Study context: reimbursement of German hospitals and the role of health insurance in the German hospital sector}

Due to the regulatory framework of health insurance in Germany, reimbursement schemes of hospitals differ by insurance type. PHI is available only to some segments of the population (ca. 20\%), namely civil servants, the self-employed, and individuals with an annual income above $48.150 €$. However, only $10 \%$ choose this option. About $>89 \%$ are covered by compulsory SHI [33]. Both types of insurance cover hospital fees. Nevertheless, hospitals can generate additional remuneration by treating PHI-holders. These are "hotelbenefits" (private rooms), costlier treatment by the chief physician, and access to innovative and costly treatment methods not available in basic SHI. However, SHI-holders have the option to purchase private supplementary health insurance (PSHI) to cover "hotel-benefits" and treatment by the chief physician. Conversely, access to innovative and costly treatment methods are not covered by PSHI. Currently 5.1 million (7.1\%) of those with SHI chose this option [33].

In 2006, all additional remuneration for these private elective services amounted to 2.5 billion euro or $4 \%$ of the total hospital revenues. On average, approximately $47 \%$ of the inpatient services are dependent on insurance status leading to higher revenues for PHIpatients compared to SHI-patients. Thus, a clear financial incentive exists to privilege PHIholders over SHI-holders.

This financial incentive to privilege PHI-holders is strengthened by two further aspects: first, PHI-holders are more sensitive towards high-quality treatment than SHI-holders [34] and [35]. Second, the way German hospitals settle fees differentiates between both insurance types: for SHI-holders, hospitals charge for diagnostic tests, treatment and drugs directly through the insurance provider. For PHI-holders, however, services such as treatment by the chief physician are charged directly by the treating physicians leading to higher revenues for themselves and their staff.

In short, several arguments can explain the financial interest of hospital management and treating physicians to privilege PHI-holders over SHI-holders: high cost pressure in the German hospital sector, additional income sources for hospitals and physicians to treat PHIpatients and PHI-patients' higher sensitivity towards quality of treatment.

\subsection{Hypotheses}

Based on Sections 1.2 and 1.3[1.2 Empirical background] and [1.3 Study context: reimbursement of German hospitals and the role of health insurance in the German hospital sector], we hypothesized that PHI-patients rated physician empathy higher than patients with SHI.

Based on the "Conceptual framework of health worker motivation" (Fig. 1), we also assumed that the type of health insurance indirectly affects physician empathy, and variables relating to contact time with the physician might play a mediating role [36].

As a secondary hypothesis, we controlled for potential socio-demographic confounders by including variables such as age and gender. We also examined as a secondary hypothesis whether patients with higher social status reported higher empathy values, i.e. patients with high school education, university degree and/or higher occupational status, which generally apply to PHI-patients. This hypothesis refers to studies showing that similarity and 
Neumann, M., Bensing, J., Wirtz, M., Wubker, A., Scheffer, C., Tauschel, D., Edelhauser, F., Ernstmann, N., Pfaff, H. The impact of financial incentives on physician empathy: a study from the perspective of patients with private and statutory health insurance. Patient Education and Counseling: 2011, 84(2), 208-216

familiarity evoke, or at least positively influence, empathy [37], [38], [39], [40], [41] and [42].

\section{METHODS}

\subsection{Study design and ethics}

This was a retrospective study with cancer patients diagnosed with bronchial, oesophageal, colorectal, breast, prostate and skin cancer. Patients with one of these diagnoses and between 18 and 75 years of age were eligible for participation. A questionnaire was sent to 710 cancer patients, who had been inpatients at the University Hospital Cologne between February and August 2005. The completely anonymous postal survey was conducted between September and November 2005. The Total-Design-Method [43], [44] and [45] was used, with three survey waves, producing a net return rate of $49.5 \%(n=326)$. Of those, three respondents $(0.9 \%)$ were excluded due to limited data quality (missing values $>30 \%$ in scale items). The study was reviewed and approved by the Ethics Committee of the Medical Faculty of the University of Cologne and by the Data Protection Authority in North-Rhine Westphalia.

\subsection{Measures}

\subsubsection{Physician empathy}

Physician empathy was assessed using the German version [46] of the widely used Scottish Consultation-and-Relational-Empathy measure (CARE) [10], [47] and [48]. The onedimensional CARE measure comprises 10 items (see http://www.gla.ac.uk/media/media 65353_en.doc) relating to patients' perception of physicians' understanding of and response to their concerns and fears. In our study, the 10 items of the CARE measure were introduced with the following sentence: "How did the physician primarily responsible for your treatment at this University Hospital behave in general?". Patients could rate the 10 items on a 5-point scale from 1 ("completely") to 5 ("not at all"). The psychometric properties of the German version of the CARE measure are very satisfactory and reported elsewhere [9] and [46].

\subsubsection{Type of health insurance}

We asked patients: "What kind of health insurance do you have?" Possible answer categories were statutory health insurance (SHI), private health insurance (PHI), statutory health insurance plus private supplementary health insurance (PSHI) or "other (e.g. insured by employment office)". As PHI- and PSHI-patients do not have the same status and receive not the same treatment in hospital (compare Section 1.4), they were not put in one group for data analysis.

\subsubsection{Cancer patients' socio-demographic characteristics}

We also asked patients about their age, gender and education level. We dichotomised the sample into those with high school education and without high school diploma (required for university) and again for those with and without a university degree. We also assessed participants' occupational status. Blue-collar workers represented the lower occupational status group and white-collar workers (employees), civil servants, self-employed persons and academics working as freelancers represented higher occupational status.

\subsubsection{Variables referring to contact time with the physician}

Cancer patients were interviewed about their subjective perception of time-related physician behaviours: 
Neumann, M., Bensing, J., Wirtz, M., Wubker, A., Scheffer, C., Tauschel, D., Edelhauser, F., Ernstmann, N., Pfaff, H. The impact of financial incentives on physician empathy: a study from the perspective of patients with private and statutory health insurance. Patient Education and Counseling: 2011, 84(2), 208-216

- "How often did you talk with the physician primarily responsible for your treatment at this University Hospital, during your stay in hospital?" (answer categories: "hardly ever "several times, but not regularly", "once a day" or "several times a day") and

- "How long was your average consultation with the physician primarily responsible for your treatment at this University Hospital?" (answer categories: "less than five minutes", "five to 10 minutes", "10 to 15 minutes", "15 to 30 minutes", "30 to 60 minutes" and "more than 60 minutes").

To assess "medical staff stress", we utilised one subscale from the widely used Cologne Patient Questionnaire [49], [50], [51] and [52] including three items, which patients could answer on a 4-point scale from 1 ("completely disagree") to 4 ("completely agree"): (1) "The hospital was busy"; (2) "The medical staff was pushed for time"; (3) "The medical staff appeared stressed".

\subsection{Data analysis}

For the 323 patients included in analysis, a total of $23(7.6 \%)$ missing values in the scale items were observed. Prior to the main data analyses, these missing values were imputed by the expectation-maximisation (EM) algorithm. The EM algorithm estimates missing data using an iterative maximum-likelihood estimation procedure. This is one of the recommended methods for preventing biases caused by not completely random missing data processes [53] and [54]. The imputation was performed using NORM software [55].

For all statistics, except for the Structural-Equation-Modeling (SEM), SPSS 17.0 was used. Based on our hypothesis (Section 1.4), we first conducted t-tests to analyse (1) whether PHIand SHI-patients differ in their subjective perception of physician empathy, and, if so, (2) whether this subjective perception was confounded by the hypothesised socio-demographic characteristics and social status of cancer patients.

Second, the two insurance groups were investigated regarding differences in variables referring to contact time with the physician (Section 2.2.4). Here, we also used t-tests.

Finally, we applied SEM to verify possible mediating effects of contact time variables (see Section 2.2.4) and confounding effects of socio-demographic and social status variables (see Section 2.2.3) [56]. Due to the ordinal measurement level of some variables, the analysis was conducted using polychoric correlations [57]. In addition, robust weighted least squares (WLS) with the mean- and variance-adjusted $\chi^{2}$ algorithm were applied using Mplus Version $4.21[58]$.

In accordance with Kline [59], a two-step SEM procedure was applied. In the first SEM step, a confirmatory factor analysis (CFA) was conducted to determine whether the intended constructs were indeed measured. The appropriateness of a specific CFA model was assessed by global fit measures.

Measures of global fit indicate whether the empirical associations among the manifest variables are appropriately reproduced by the model [59] and [60]. For a variety of these global fit measures, certain criteria have to be met for accepting the model under study as plausible and parsimonious. Measures of absolute fit, such as the Root Mean Square Error of Approximation (RMSEA) can be interpreted as the amount of information within the empirical covariance matrix that cannot be explained by the proposed model. Furthermore, measures of incremental fit were employed [61]: the Comparative Fit Index (CFI) and the Tucker-Lewis index (TLI).

In the second SEM step, we specified a measurement model and two path models, as implied by the results of the first step of our analysis, and evaluated it using global fit measures. In the first path model, we tested only the direct path from "PHI or SHI" to "CARE". In the mediated path model, we included the mediator variables referring to contact time with the physician - except of "average length of consultation" because of its skewed distribution (see Table 5) — to compare all models, thereby gaining evidence for mediating effects. The significance of the relationships between the exogenous and 
Neumann, M., Bensing, J., Wirtz, M., Wubker, A., Scheffer, C., Tauschel, D., Edelhauser, F., Ernstmann, N., Pfaff, H. The impact of financial incentives on physician empathy: a study from the perspective of patients with private and statutory health insurance. Patient Education and Counseling: 2011, 84(2), 208-216

endogenous latent variables as well as the amount of variance explained in the endogenous variables was examined.

In the last step, we also controlled for possible confounding effects of the sociodemographic and social status variables. That is to say, we verified if the relationships in our structural model changed based on the amount of another variable added to the model [36] and [56]. Multi-group SEM is used to test moderating effects [56]. In this study, a multigroup SEM model was conducted with Mplus Version 4.21 [58].

\section{RESULTS}

\subsection{Cancer patients' characteristics}

Participants' mean age was 58.7 years $(\mathrm{SD}=11.2$; range $=19-76)$ with $64.5 \%$ of patients over 50 years. Almost half (47.7\%) were women; $78.6 \%$ lived with a partner, and of those, $69.4 \%$ were married. High school was the highest education level reached by $32.2 \%$ of participants.

Disease-specific characteristics of this sample are reported in Table 1. Table 2 shows the distribution of the different types of health insurance. Compared with SHI-patients, PHIpatients had better schooling, more academic degrees, higher occupational status and better global quality of life (see Table 3 ).

\section{[TABLE 1] [TABLE 2] [TABLE 3]}

\section{2. t-Tests}

Table 4 shows that PHI-patients rated physicians' empathy significantly higher than SHIpatients. Female cancer patients also reported significantly higher values of physicians' empathy higher than male patients. Contrary to our hypothesis, patients of lower social status did not differ in their rating of physician empathy (see Table 4, rows 3-5). Thus, the aforementioned relationship between type of health insurance and physician empathy was confounded only by gender, but not by the hypothesized social status, although patients with PHI had significantly better schooling, more academic degrees, and higher occupational status (see Table 3).

\section{[TABLE 4] [TABLE 5]}

Results in Table 5 demonstrate that PHI-patients reported talking significantly more frequently with their physician during their stay in hospital, although the average length of each consultation was not longer. In other words, this result indicates that the amount of time a physician spent with a PHI-patient is in total more, because he/she saw these patients more frequently than SHI-patients. Conversely, physicians did not spend more time in each single consultation with PHI-patients.

\subsection{SEM and mediator analysis}

We conducted a CFA with the model in Fig. 2 resulting in a very good global data fit (see Table 6, "measurement model (CFA)") with very good factor loadings (see Fig. 2). These measurement indicators show a reliable estimation of all constructs. The excellent CFI, TLI and RMSEA values indicate a very good model fit (see Table 6). Furthermore, the onedimensional structure of the CARE measure could be replicated, but the error term correlation of items 4 and 5, as well as 9 and 10 [9], [10] and [46] did not necessary exist in this model.

\section{[FIGURE 2] [TABLE 6]}

After ensuring a satisfactory measurement quality, structural relationships between variables were specified, as implied by our hypotheses. The two path models (see Table 6) 
Neumann, M., Bensing, J., Wirtz, M., Wubker, A., Scheffer, C., Tauschel, D., Edelhauser, F., Ernstmann, N., Pfaff, H. The impact of financial incentives on physician empathy: a study from the perspective of patients with private and statutory health insurance. Patient Education and Counseling: 2011, 84(2), 208-216

yielded virtually the same measures of global fit as the "CFA model", demonstrating that the model structures were in accordance with the empirical data.

Testing the first path model (see Table 6 "path model: PHI or SHI -> CARE"), a very goblde model fit was reached (see Table 6). Fig. 2 illustrates the "mediated path model", indicating estimated significant path coefficients and the percentage of explained variances for the endogenous structural variables. The mediated path model (see Table 6) demonstrates that PHI has a significant strong effect on frequency of talking with the physician, which in turn

(1) has a strong significant effect on the quality of subjectively perceived physician empathy (see

Fig. 2) and

(2) has also a moderate significant effect of patients' perception of medical staff stress, in turn, again moderately influencing patients' rating of physician empathy (see

Fig. 2).

To test the mediating effects of the two contact time variables, we put direct paths from "PHI or SHI" to "CARE" and from "PHI or SHI" to "medical staff stress" in this mediated path model, which were no longer significant (see Fig. 2, grey paths). Thus, the direct paths from "PHI or SHI" to "CARE" and from "PHI or SHI" to "medical staff stress" could be eliminated from the structural model without losing any systematic information. Therefore, our hypothesis that PHI has an indirect effect on physician empathy via mediating variables referring to contact time with the physician could be verified.

Last, we specified patients' gender as a confounding variable and conducted a multi-group analysis to verify a possible confounding effect. The result was that there were no group differences (overall model: $\mathrm{df}=2, \mathrm{CMIN}=0.666, \mathrm{p}=0.700$ ) between male and female cancer patients that affect the direction and/or strength of the relationship between the variables in the model.

\section{DISCUSSION AND CONCLUSION}

\subsection{Discussion}

Our findings suggest that PHI-status is one necessary precondition for physicians spending more time with the patient. Spending more time with the PHI-patient has two major effects: it results in a more positive perception of physician empathy and positively impacts PHIpatients' perception of medical staff stress and positively influences physician empathy. These results seem to support the investigated parts of the "Conceptual model of health worker motivation" [15] (see Fig. 1) and most of the aforementioned empirical studies (see Section 1.2): we can speculate that if patients' PHI-status gives the hospitals and physicians the opportunity to charge more, this indirectly impacts their motivation to empathise (see Fig. 1) via mediating variables that reflect devoting more time to patients and being less stressed as a physician.

The mediating effect of spending more time with the patient is in line with Kao et al. [28], who examined the relationship between physician payment method and patient trust: patients' reports of physician behaviour accounted for part of the variation in patients' trust in physicians who were paid differently. The authors concluded that the impact of payment methods on patient trust might be mediated partly by physician behaviour. They found that differences in trust by payment method were reduced when the Picker Score, comprising time-related items of physician behaviour, was included in the regression analysis [28].

The influence of patients' perception of medical staff stress on physician empathy was also found in a former study of Neumann and colleagues with the same sample of cancer patients [9]. However, the impact of PHI-status as one precondition for spending more time with the patient, thereby influencing patients' perception of medical staff stress is a new relationship that was found according to the "Conceptual framework of health worker motivation" by Franco et al. [15]. Nevertheless, Braddock and colleagues [62] also discussed this issue: "In 
Neumann, M., Bensing, J., Wirtz, M., Wubker, A., Scheffer, C., Tauschel, D., Edelhauser, F., Ernstmann, N., Pfaff, H. The impact of financial incentives on physician empathy: a study from the perspective of patients with private and statutory health insurance. Patient Education and Counseling: 2011, 84(2), 208-216

terms of adverse effects of time pressure, the physician [...] may exhibit signs of stress or annoyance that, while not directed at the patient, can nonetheless be perceived so. Patients may question whether the physician really cares if the physician seems annoyed, rushedndive inattentive." (p. 1059).

Applying our findings on a societal level raises questions of equality of opportunity to receive high-quality patient-centred care. It seems that higher income patients receive more time with their physician, and, consequently, more empathy. These questions of social inequality are even more crucial because physician empathy is a determinant for better health outcomes (see Section 1) and the Institute of Medicine (IOM) classifies patient-centred care as one of six central targets for health systems in the 21 st century, by the following definition: “...qualities of compassion, empathy, and responsiveness to the needs, values, and expressed preferences of the individual patient" [1, p. 48]. In other words, patients deserve sensitivity to their needs, regardless of whether their health insurance provider is private or state-regulated [25]. Therefore, the impact of time and money seems to be one important factor in patients' rating of physician empathy that requires intense discussion in healthcare policy.

\subsection{Strengths and limitations of this study}

Our study has several important strengths. The hypothesis was based on theory: on the "Conceptual framework of health worker motivation" (Fig. 1) and on previous empirical findings (see Section 1.2). Furthermore, our results were controlled for important confounding variables (see Section 3.3). Moreover, this study is one of the few examining provider payment as a determinant for quality of care in the patient-physician relationship, especially for physician empathy.

Regarding the study design, it is noteworthy that participants were blinded to any specific study hypothesis, and all analysed variables were not mentioned in the survey cover letter. Although the quality of retrospective studies is not necessarily high, and randomised controlled trials (RCTs) are the most rigorous type of study design, two main reasons can explain their impracticability in this research area. First, few physicians would be willing to participate in RCTs where their income was randomly determined. Second, it would be impossible to blind the physicians as to their payment method [17]. Furthermore, a prospective study design would not constitute a genuine improvement, because health insurance type is a fixed variable, and combined with our theoretical background, we can assume high evidence of the supposed direction of causality in our model (see Fig. 2) [56].

However, we are aware of various study limitations. First, although patients were asked to focus on the physician primarily responsible for their treatment at the University Hospital Cologne, we knew neither which specific physician and consultation experiences were recalled, nor if patients' recall was accurate. Face-to-face interviews during hospital stay would possibly improve their recall, but would simultaneously increase the chance of social desirability bias.

Second, the cross-sectional design, as well as the postal survey form, might lead to a biased selection of cancer patients. A non-responder analysis could not be conducted due to the need to preserve participant anonymity.

Third, including only one hospital in our study limits the scope for generalizing the findings to other hospitals in Germany, because other hospitals might have a different policy concerning the way they treat PHI- and SHI-patients.

Fourth, as $22 \%$ of our cancer patients had a PHI, we have to admit a selection bias. It might be that these patients, who are also better educated, were more likely to respond to our questionnaire or that the University Hospital Cologne purposefully select these highly profitable patients.

Fifth, important variables mentioned in the conceptual model (see Fig. 1), were not assessed in our study, e.g. health worker motivation and health worker capability. In 
Neumann, M., Bensing, J., Wirtz, M., Wubker, A., Scheffer, C., Tauschel, D., Edelhauser, F., Ernstmann, N., Pfaff, H. The impact of financial incentives on physician empathy: a study from the perspective of patients with private and statutory health insurance. Patient Education and Counseling: 2011, 84(2), 208-216

addition, other confounders influencing the relationship between physician empathy and health insurance types were not involved, such as income level, common culture of physician and patient, patients' social environment, etc.

Finally, the applied construct measuring "frequency of talking with physician" should be assessed via several data sources (patients, physicians, observer) to ensure a more reliable and valid measurement.

\subsection{Conclusions}

This study, conducted from the patients' perspective, adds two important findings, which should be recognized by health policy and medical educators:

1. Time seems to play a crucial role in providing empathy in the clinical encounter, i.e. for high-quality healthcare.

2. Money (as represented by PHI) appears one central resource for healthcare organisations/healthcare policy to influence physicians in their decision to devote more time to private patients (see

Fig. 1 "organisational factors").

These conclusions lead us to Bishop and Rees's [63] hypothesis that altruistic dimensions are generally best understood as a social construction to mask the reality of financial reward for care.

\subsection{Practical implications}

As reflected by Franco et al. [16], excessive focus on financial incentives can lead to distortions in physicians' effort. They might lead to specific types of work outputs, but financial rewards alone are unlikely to be effective in improving the quality of individual and organisational performance. Physician empathy, in particular, is determined by several biographical and situational factors, which need to be recognized [9] and [11]. Franco et al. [16] conclude that integration of financial incentives with other incentives and interventions might create a more balanced approach, increasing motivation, satisfaction and performance.

\subsection{Future research}

In the light of our fifth study limitation, the other variables in the "Conceptual model of health worker motivation" (Fig. 1) should be integrated in future studies, assessed by different types of data sources (e.g. patient, physician, hospital) to receive high data validity. An investigation of these research questions more and different types of hospitals, in other countries, with different health policies and in patients with different diagnoses would be of particular interest, as each country's experience is different and a universal blueprint of health worker motivation does not exist [16].

\section{ACKNOWLEDGMENTS}

We thank all patients who participated in this study and the physicians of the University Hospital Cologne for supporting this survey. Furthermore, we are grateful to the Else Kröner-Fresenius Foundation for its idealistic and financial support of this study (grant number P43/05//A33/05/F0). Melanie Neumann is supported by a grant from the Software AG Foundation, Germany.

Moreover, we are grateful to both anonymous reviewers for their very constructive feedback and their valuable advice that contributed to improving the paper.

Portions of the study have been presented at the International Conference on Communication in Healthcare (ICCH, October 2009) in Miami, FL.

\section{REFERENCES}

[1] Institute of Medicine, Crossing the quality chasm: a new health system for 21st century, National Academy Press, Washington, DC (2001). 
Neumann, M., Bensing, J., Wirtz, M., Wubker, A., Scheffer, C., Tauschel, D., Edelhauser, F., Ernstmann, N., Pfaff, H. The impact of financial incentives on physician empathy: a study from the perspective of patients with private and statutory health insurance. Patient Education and Counseling: 2011, 84(2), 208-216

[2] R.W. Squier, A model of empathic understanding and adherence to treatment regimens in practitioner-patient-relationships, Soc Sci Med 30 (1990), pp. 325-329.

[3] J.C. Rees-Lewis, Patients views on quality of care in general practice: literature revieqvive Soc Sci Med 39 (1994), pp. 655-671.

[4] D.M. Dixon, K.G. Sweeney and D.J.P.P. Gray, The physician healer: ancient magic or modern science?, Br J Gen Pract 49 (1999), pp. 309-312.

[5] T. Usherwood, Understanding the consultation: evidence, theory and practice, Oxford University Press, Oxford (1999).

[6] H.M. Adler, The sociophysiology of caring in the doctor-patient relationship, J Gen Intern Med 17 (2002), pp. 883-890.

[7] C.L. Bylund and G. Makoul, Empathic communication and gender in the physicianpatient encounter, Patient Educ Couns 48 (2002), pp. 207-216.

[8] S. Herzig, L. Biehl, H. Stelberg, C. Hick, N. Schmeißer and A. Koerfer, What makes a good doctor? A content analysis of assessments by a sample of doctors, Dtsch Med Wochenschr 131 (2006), pp. 2883-2888.

[9] M. Neumann, M. Wirtz, E. Bollschweiler, M. Warm, J. Wolf and H. Pfaff, Determinants and patient-reported long-term outcomes of physician empathy in oncology: a structural equation modelling approach, Patient Educ Couns 69 (2007), pp. 63-75.

[10] S.W. Mercer, M. Neumann, M. Wirtz, B. Fitzpatrick and G. Vojt, General practitioner empathy, patient enablement, and patient-reported outcomes in primary care in an area of high socio-economic deprivation in Scotland: a pilot prospective study using structural equation modelling, Patient Educ Couns 73 (2008), pp. 240-245.

[11] M. Neumann, J. Bensing, S.W. Mercer, N. Ernstmann and H. Pfaff, Analyzing the "nature" and "specific effectiveness" of clinician empathy: a theoretical overview and contribution towards a theory-based research agenda, Patient Educ Couns 74 (2009), pp. 339-346.

[12] S.W. Mercer and W.J. Reynolds, Empathy and quality of care, Br J Gen Pract 52 (2002), pp. S9-S13.

[13] D.P. Rakel, T.J. Hoeft, B.P. Barrett, B.A. Chewning, B.M. Craig and M. Niu, Practitioner empathy and the duration of the common cold, Fam Med 41 (2009), pp. 494-501.

[14] F. Hertzberg, B. Mausner and B. Snyderman, The motivation to work, Wiley, New York (1959).

[15] L.M. Franco, S. Bennett and R. Kanfer, Health sector reform and public sector health worker motivation: a conceptual framework, Soc Sci Med 54 (2002), pp. 1255-1266.

[16] L.M. Franco, S. Bennett, R. Kanfer and P. Stubblebine, Determinants and consequences of health worker motivation in hospitals in Jordan and Georgia, Soc Sci Med 58 (2004), pp. 343-355.

[17] T. Gosden, L. Pedersen and D. Torgerson, How should we pay doctors? A systematic review of salary payments and their effect on doctor behaviour, Q J Med 92 (1999), pp. 4755.

[18] W.R. Smith, Evidence for the effectiveness of techniques to change physician behavior, Chest 118 (2000), pp. 8S-17S.

[19] N. Lurie, J. Christianson, M. Finch and I. Moscovice, The effects of capitation on health and functional status of the Medicaid elderly: a randomized trial, Ann Intern Med 120 (1994), pp. 506-511.

[20] J.E. Sisk, S.A. Gorman, L.A. Reisinger, S.A. Glied, W.H. Du-Mouchel and M.M. Hynes, Evaluation of Medicaid managed care: satisfaction, access, and use, J Am Med Assoc 276 (1996), pp. 50-55.

[21] H.R Miller and H.S. Luft, Does managed care lead to better or worse quality of care? A survey of recent studies shows mixed results on managed care planned performance, Health Aff (Millwood) 16 (1997), pp. 7-25.

[22] M.H. Katz, R. Marx, J.M. Douglas Jr., G.A. Bolan, M.-S. Park and R.J. Gurley et al., Insurance type and satisfaction with medical care among HIV-infected men, J Acquir Immune Defic Syndr Hum Retrovirol 14 (1997), pp. 35-43.

[23] W. Branch, Is the therapeutic nature of the patient-physician relationship being undermined?, Arch Intern Med 160 (2000), pp. 2257-2260. 
Neumann, M., Bensing, J., Wirtz, M., Wubker, A., Scheffer, C., Tauschel, D., Edelhauser, F., Ernstmann, N., Pfaff, H. The impact of financial incentives on physician empathy: a study from the perspective of patients with private and statutory health insurance. Patient Education and Counseling: 2011, 84(2), 208-216

[24] K. Davis, K.S. Collins, C. Schoen and C. Morris, Choice matters: enrollees' views of their health plans, Health Aff (Millwood) 14 (2005), pp. 99-112.

[25] R.C. Leventhal, HMO versus private care medical systems: a study to determine theive aging consumers' satisfaction with medical care under these two systems, Health Mark Q 9 (1992), pp. 51-66.

[26] S. Chlabicz and L. Marcinowicz, Public or non-public family medicine-patients' perspective of the quality of primary care in Bialystok, Poland, Eur J Gen Pract 11 (2005), pp. 5-10.

[27] T. Sawicki, Quality of health care in Germany. A six-country comparison, Med Klin 100 (2005), pp. 755-768.

[28] A.C. Kao, D.C. Green, A.M. Zaslavsky, J.P. Koplan and P.D. Cleary, The relationship between method of physician payment and patient trust, J Am Med Assoc 280 (1998), pp. 1708-1714.

[29] R. Sturm, L.S. Meredith and K.B. Wells, Provider choice and continuity for the treatment of depression, Med Care 34 (1996), pp. 723-734

[30] A.M. van Dulmen, Physician reimbursement and the medical encounter: an observational study in Dutch pediatrics, Clin Pediatr 39 (2000), pp. 591-601.

[31] T. Gosden, F. Forland, I.S. Kristiansen, M. Sutton, B. Leese and A. Giuffrida et al., Impact of payment method on behaviour of primary care physicians: a systematic review, J Health Serv Res Policy 6 (2001), pp. 44-55.

[32] G.B. Hickson, W.A. Altemeier and J.M. Perrin, Physician reimbursement by salary or fee-for-service: effect on physician practice behavior in a randomized prospective study, Pediatrics 80 (1987), pp. 344-350.

[33] Verband der deutschen Krankenversicherung e.V. Zahlenbericht der privaten Krankenversicherung [Association of the German Health Insurance]. Indices report of the private Health Insurance; 2006/2007.

[34] T. Besley, J. Hall and I. Preston, The demand for private health insurance: do waiting lists matter?, J Public Econ 72 (1999), pp. 155-181.

[35] W.C. Tai, F.W. Porell and E.K. Adams, Hospital choice of rural medicare beneficiaries: patient, hospital attributes, and the patient-physician relationship, Health Serv Res 39 (2004), pp. 1903-1922.

[36] R.M. Baron and D.A. Kenny, The moderator-mediator variable distinction in social psychological research: conceptual, strategic, and statistical considerations, J Pers Soc Psychol 51 (1986), pp. 1173-1182.

[37] D.L. Krebs, Empathy and altruism, J Pers Soc Psychol 32 (1975), pp. 1134-1146.

[38] Y. Kubo and T. Muto, The effect of recalling one's own similar experiences on empathic understanding of the feeling of another person, Jpn J Educ Psychol 32 (1984), pp. 296305.

[39] M.A. Barnett, Similarity of experience and empathy in prescholars, J Genet Psychol 145 (1984), pp. 241-250.

[40] M.A. Barnett, P.A. Tetreault, J.A. Esper and A.R. Bristow, Similarity and empathy: the experience of rape, J Soc Psychol 126 (1986), pp. 47-49.

[41] M.A. Barnett, P.A. Tetreault and I. Masbad, Empathy with a rape victim: the role of similarity of experience, Violence Vict 2 (1987), pp. 255-262. [42] C.D. Batson, S.C. Sympson, J.L. Hindman, P. Decruz, R.M. Todd and J.L. Weeks et al., I've been there too: effect on empathy of prior experience with a need, Pers Soc Psychol Bull 22 (1996), pp. 474-482.

[43] D.A. Dillman, Mail and telephone surveys. The total design method, John Wiley \& Sons, New York (1978).

[44] D.A. Dillman, Mail and Internet surveys, John Wiley \& Sons, New York (2000).

[45] D.A. Dillman, J.D. Smyth and L.M. Christian, Internet, mail, and mixed-mode surveys: the tailored design method, John Wiley \& Sons, Hoboken, New Jersey (2008).

[46] M. Neumann, M. Wirtz, E. Bollschweiler, M. Warm, J. Wolf and H. Pfaff, Psychometrische Evaluation der deutschen Version des Messinstruments "Consultation and Relational Empathy" (CARE) am Beispiel von Krebspatienten, Psychometric evaluation of the German version of the "Consultation and Relational Empathy" (CARE) at the example of cancer patients, Psychother Psychosom Med Psychol 58 (2008), pp. 5-15. 
Neumann, M., Bensing, J., Wirtz, M., Wubker, A., Scheffer, C., Tauschel, D., Edelhauser, F., Ernstmann, N., Pfaff, H. The impact of financial incentives on physician empathy: a study from the perspective of patients with private and statutory health insurance. Patient Education and Counseling: 2011, 84(2), 208-216

[47] S.W. Mercer, M. Maxwell, D. Heaney and G.C. Watt, The Consultation and Relational Empathy (CARE) measure: development and preliminary validation and reliability of an empathy-based consultation process measure, Fam Prac 21 (2004), pp. 1-6.

[48] S.W. Mercer, A. McConnachie, M. Maxwell, D. Heaney and G.C. Watt, Relevance and practical use of the Consultation and Relational Empathy (CARE) measure in general practice, Fam Prac 22 (2005), pp. 328-334.

[49] H. Pfaff, Der Kölner Patientenfragebogen: Theoretischer Rahmen, Konstrukte und Messinstrumente, The Cologne Patient Questionnaire: Theory, constructs and measures. In: H. Pfaff, D.C. Freise, G. Mager and M. Schrappe, Editors, Der Kölner Patientenfragebogen (KPF): Entwicklung und Validierung eines Fragebogens zur Erfassung der Einbindung des Patienten als Kotherapeuten, The Cologne Patient Questionnaire (CPQ): Development and Validation of a questionnaire to assess the patient as a co-therapist, Asgard-Verlag, Sankt Augustin (2003), pp. 7-27.

[50] H. Pfaff, P. Steffen, A. Brinkmann, J. Lütticke and A. Nitzsche, Der Kölner Patientenfragebogen (KPF). Kennzahlenhandbuch, The Cologne Patient Questionnaire (CPQ), Handbook of indices, Veröffentlichungsreihe der Abteilung Medizinische Soziologie des Instituts für Arbeitsmedizin, Sozialmedizin und Sozialhygiene der Universität zu Köln (2004).

[51] O. Ommen, M. Wirtz, C. Janssen, M. Neumann, E. Driller and N. Ernstmann et al., Psychometric evaluation of an instrument to assess patient-reported "psychosocial care by physicians": a structural equation modelling approach, Int J Qual Health Care (2009)

[52] O. Ommen, M. Wirtz, C. Janssen, M. Neumann, N. Ernstmann and H. Pfaff, Validation of a theory-based instrument measuring patient-reported psychosocial care by physicians using a multiple indicators and multiple causes model, Patient Educ Couns (2009) [Epub ahead of print].

[53] P.D. Allison, Missing data, Sage, Thousand Oaks (2001).

[54] J.L. Schafer and J.W. Graham, Missing data: our view of the state of the art, Psychol Methods 7 (2002), pp. 147-177.

[55] J.W. Graham, P.E. Cumsille and E. Elek-Fisk, Methods for handling missing data. In: J.A. Schinka and W.F. Velicer, Editors, Research methods in psychology, Wiley, New York (2003), pp. 87-114.

[56] J.F. Hair, R.E. Anderson, R.L. Tatham and W.C. Black, Multivariate data analysis, Prentice Hall, Upper Saddle River, New Jersey (2006).

[57] R. MacCallum, S. Zhang, K.J. Preacher and D.D. Rucker, On the practice of dichotomization of quantitative variables, Psychol Methods 7 (2002), pp. 19-40.

[58] Muthen B, du Troit SHC, Spisic D. Robust inference using weighted least squares and quadratic estimating equations in latent variable modeling with categorial and continuous outcomes. Unpublished manuscript. Available at 1997.

[59] R.B Kline, Principles and practice of structural equation modeling, Guilford, New York (2005).

[60] A. Boosma, Reporting analyses of covariance structures, Struct Eq Modeling 7 (2000), pp. 461-483.

[61] B.G. Tabachnik and L.S. Fidell, Using multivariate statistics, Harper Collins, New York (1996).

[62] C.H. Braddock and L. Snyder, The doctor will see you shortly. The ethical significance of time for the patient-physician relationship, J Gen Intern Med 20 (2005), pp. 1057-1062.

[63] J.P. Bishop and C. Rees, Hero or has-been: is there a future for altruism in medical education?, Adv Health Sci Educ Theory Pract 12 (2007), pp. 391-399.

[64] N.K. Aaronson, S. Ahmedzai, B. Bergman, M. Bullinger, A. Cull and N.J. Duez et al., The European Organisation for Research and Treatment of Cancer QLQ-C30: a quality-oflife instrument for use in international clinical trials in oncology, J Natl Cancer Inst 85 (1993), pp. 365-376.

[65] R. Bagozzi and H. Baumgartner, The evaluation of structural equation models and hypothesis testing. In: R. Bagozzi, Editor, Principles of marketing research, Blackwell Publishers, Cambridge (1994), pp. 386-422. 
Neumann, M., Bensing, J., Wirtz, M., Wubker, A., Scheffer, C., Tauschel, D., Edelhauser, F., Ernstmann, N., Pfaff, H. The impact of financial incentives on physician empathy: a study from the perspective of patients with private and statutory health insurance. Patient Education and Counseling: 2011, 84(2), 208-216

\section{TABLES AND FIGURES}

Figure 1
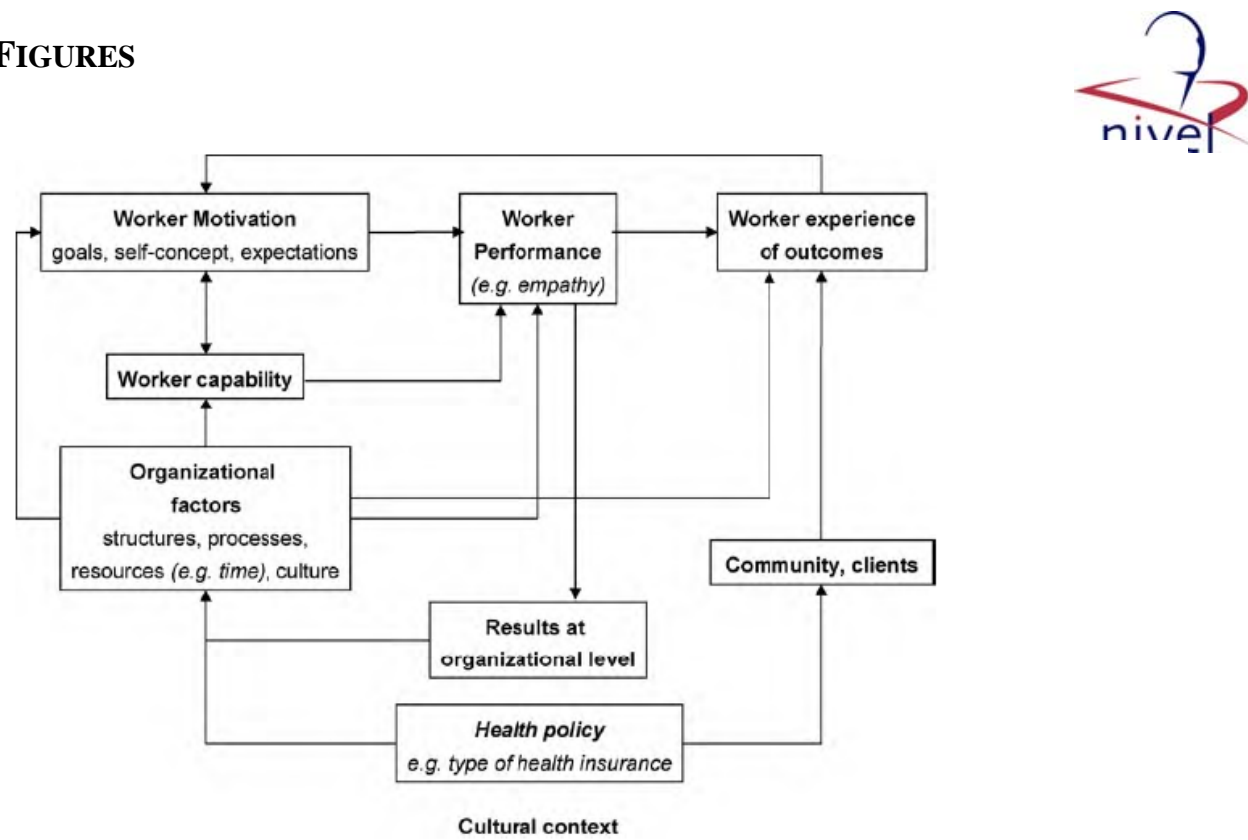

Fig. 1. Conceptual framework of health worker motivation (drawing closely on Franco et al. [15]; words in italics were changed or added; the term in the original was "Health Sector Reform" instead of "Health policy"). 
Neumann, M., Bensing, J., Wirtz, M., Wubker, A., Scheffer, C., Tauschel, D., Edelhauser, F., Ernstmann, N., Pfaff, H. The impact of financial incentives on physician empathy: a study from the perspective of patients with private and statutory health insurance. Patient Education and Counseling: 2011, 84(2), 208-216

\section{Table 1}

Table 1

Disease-specific characteristics of the sample $(N=323)$.

\begin{tabular}{|c|c|c|c|}
\hline Type of cancer diagnosis & & $N$ & $\%$ \\
\hline Bronchial & & 28 & 8.7 \\
\hline Colorectal & & 18 & 5.6 \\
\hline Prostate & & 54 & 16.7 \\
\hline Oesophageal & & 35 & 10.8 \\
\hline Breast & & 109 & 33.7 \\
\hline Skin & & 68 & 21.1 \\
\hline Other & & 7 & 2.2 \\
\hline Missing & & 4 & 1.2 \\
\hline Cancer stage & & $N$ & $\%$ \\
\hline Initial diagnosis & & 199 & 61.6 \\
\hline Relapse & & 29 & 9.0 \\
\hline Second tumour & & 36 & 11.1 \\
\hline Relapse and second tumour & & 17 & 5.2 \\
\hline Don't know which cancer stage & & 27 & 8.4 \\
\hline Other cancer stage & & 8 & 2.5 \\
\hline Missing & & 7 & 2.2 \\
\hline Therapy/treatment & & $N$ & $\%$ \\
\hline Surgical & & 283 & 87.6 \\
\hline Chemo & & 143 & 44.3 \\
\hline Radio & & 148 & 45.8 \\
\hline Pain & & 24 & 7.4 \\
\hline Antihormone & & 61 & 18.9 \\
\hline Antibodies & & 6 & 1.9 \\
\hline Complementary & & 17 & 5.3 \\
\hline No therapy ("wait and see") & & 18 & 5.6 \\
\hline Other & & 25 & 7.7 \\
\hline Missing & & - & - \\
\hline Time since diagnosis & M & Range & SD \\
\hline Months & 22.1 & $1-309$ & 44.8 \\
\hline
\end{tabular}

Note: $M=$ mean, $\mathrm{SD}=$ standard deviation.

Table 2

Table 2

Type of health insurance $(N=323)$.

\begin{tabular}{lrr}
\hline Type of health insurance & \multicolumn{1}{c}{$N$} & $\%$ \\
\hline Statutory health insurance (SHI) & 211 & 65 \\
Private health insurance (PHI) & 71 & 22 \\
SHI plus private supplementary health insurance (PSHI) & 41 & 13 \\
Other (e.g. insured by employment office) & 0 & 0 \\
\hline
\end{tabular}


Neumann, M., Bensing, J., Wirtz, M., Wubker, A., Scheffer, C., Tauschel, D., Edelhauser, F., Ernstmann, N., Pfaff, H. The impact of financial incentives on physician empathy: a study from the perspective of patients with private and statutory health insurance. Patient Education and Counseling: 2011, 84(2), 208-216

\section{Table 3}

Characteristics of respondents regarding their health insurance status.

\begin{tabular}{|c|c|c|c|c|}
\hline & $\begin{array}{l}\text { Statutory health } \\
\text { insurance (SHI) } \\
N(\%)\end{array}$ & $\begin{array}{l}\text { Private health } \\
\text { insurance (PHI) } \\
N(\%)\end{array}$ & $\begin{array}{l}\text { SHI plus private supplementary } \\
\text { health insurance } \\
N(\%)\end{array}$ & $p$-Value \\
\hline Female & $107(49.3)$ & $28(51.9)$ & $26(65)$ & 0.190 \\
\hline Age, mean & 59 & 57 & 60 & 0.555 \\
\hline High school education & $52(25.2)$ & $32(59.3)$ & $19(47.5)$ & 0.000 \\
\hline Academic degree & $36(17.9)$ & $28(52.8)$ & $10(27)$ & 0.000 \\
\hline Blue-collar workers & $64(29.5)$ & $2(3.7)$ & $2(5)$ & 0.000 \\
\hline Duration of hospital stay: more than 10 days & $107(50.5)$ & $20(37)$ & $16(41)$ & 0.156 \\
\hline No secondary diseases & $93(42.9)$ & $30(56.6)$ & $20(50)$. & 0.174 \\
\hline Cancer stage: initial diagnosis & $125(66.7)$ & $38(74.5)$ & $28(71.8)$ & 0.513 \\
\hline Global $\mathrm{Qol}^{2}$, mean & 9.27 & 10.37 & 9.63 & 0.038 \\
\hline
\end{tabular}

${ }^{2}$ Global Ouality of life (Ool) was assessed with item number 30 of the EORTC questionnaire called "global health status" [64]

\section{Table 4}

Table 4

$t$-Tests with physician empathy as dependent variable, lower values show higher empathy.

\begin{tabular}{|c|c|c|c|c|c|c|c|}
\hline \multirow[t]{2}{*}{ Variable } & \multirow[t]{2}{*}{ Group $(N)$} & \multirow[t]{2}{*}{$\begin{array}{l}\text { Mean } \\
\text { CARE-score }\end{array}$} & \multicolumn{2}{|c|}{$\begin{array}{l}\text { Levene's test for } \\
\text { equality of variances }\end{array}$} & \multirow{2}{*}{$\begin{array}{l}p \text {-Value (2-tailed) } \\
p\end{array}$} & \multicolumn{2}{|c|}{ 95\% confidence interval } \\
\hline & & & $F$ & $p$ & & Lower limit & Higher limit \\
\hline Type of health insurance & $\begin{array}{l}\text { SHI (211) } \\
\text { PHI (71) }\end{array}$ & $\begin{array}{l}2.39 \\
1.87\end{array}$ & 5.269 & 0.022 & 0.001 & -0.816 & -0.213 \\
\hline School education & $\begin{array}{l}\text { Higher (103) } \\
\text { Lower (201) }\end{array}$ & $\begin{array}{l}2.14 \\
2.31\end{array}$ & 0.988 & 0.321 & 0.187 & -0.865 & 0.437 \\
\hline Academic degree & $\begin{array}{l}\text { Yes (74) } \\
\text { No (218) }\end{array}$ & $\begin{array}{l}2.15 \\
2.31\end{array}$ & 1.495 & 0.222 & 0.289 & -0.135 & 0.453 \\
\hline Occupational status & $\begin{array}{l}\text { Higher (254) } \\
\text { Lower (69) }\end{array}$ & $\begin{array}{l}2.26 \\
2.39\end{array}$ & 0.427 & 0.517 & 0.388 & -0.166 & 0.428 \\
\hline Age & $\begin{array}{l}<60(129) \\
>60(134)\end{array}$ & $\begin{array}{l}2.15 \\
2.28\end{array}$ & 1.701 & 0.193 & 0.336 & -0.132 & 0.387 \\
\hline Sex & $\begin{array}{l}\text { Female (167) } \\
\text { Male (156) }\end{array}$ & $\begin{array}{l}2.13 \\
2.46\end{array}$ & 1.299 & 0.255 & 0.014 & -0.548 & -0.062 \\
\hline
\end{tabular}

Note: CARE-score $=10$ items of the physician empathy measure ( see Section 2.2.1) added up and divided by 10.

\section{Table 5}

$t$-Tests with type of health insurance as dependent variable (PHI: $N=71, S H I: N=211$ )

\begin{tabular}{|c|c|c|c|c|c|c|c|}
\hline \multirow[t]{2}{*}{ Variables } & \multirow[t]{2}{*}{ Group } & \multirow[t]{2}{*}{ Mean } & \multicolumn{2}{|c|}{$\begin{array}{l}\text { Levene's test for } \\
\text { equality of variances } \\
\end{array}$} & \multirow[t]{2}{*}{ p-Value (2-tailed) } & \multicolumn{2}{|c|}{ 95\% confidence interval } \\
\hline & & & $F$ & $p$ & & Lower limit & Higher limit \\
\hline Frequency of talking with physician & $\begin{array}{l}\text { SHI } \\
\text { PHI }\end{array}$ & $\begin{array}{l}2.28 \\
2.81\end{array}$ & 0.877 & 0.350 & 0.000 & 0.288 & 0.768 \\
\hline $\begin{array}{l}\text { Average length of } \\
\text { consultation with physician }\end{array}$ & $\begin{array}{l}\text { SHI } \\
\text { PHI }\end{array}$ & $\begin{array}{l}2.65 \\
2.32\end{array}$ & - & - & 0.334 & - & - \\
\hline Medical staff stress & $\begin{array}{l}\text { SHI } \\
\text { PHI }\end{array}$ & $\begin{array}{l}2.51 \\
2.37 \\
\end{array}$ & 9.931 & 0.002 & 0.170 & -0.340 & 0.061 \\
\hline
\end{tabular}

${ }^{2}$ Here the Kruskal-Wallis test was used because of the skewed distribution of the variable.

\section{Table 6}

Measures of global fit for all models estimated.

\begin{tabular}{llllllll}
\hline & $\chi^{2}$ & $\mathrm{df}$ & $p$ & $\chi^{2} / \mathrm{df}$ & TLI & CFI & RMSEA \\
\hline Thresholds of acceptable fit & & & $>.05$ & $<2$ & $\geq .95$ & $\geq .95$ & $\leq .070$ \\
Measurement model (CFA) & 99.57 & 52 & $<.001$ & 3.11 & 1.00 & .99 & .062 \\
Path model: PHI or SHI -> CARE (grey path Fig. 2) & 93.39 & 47 & $<.001$ & 3.46 & 1.00 & .99 & .062 \\
Mediated path model (see Fig. 2) & 68.56 & 51 & $<.001$ & 2.21 & 1.00 & .99 & .062
\end{tabular}

Note: $\mathrm{TLI}=$ Tucker-Lewis Index, $\mathrm{CFI}=$ Comparative Fit Index, RMSEA = Root Mean Square Error of Approximation. For thresholds of acceptable fit see [56,65]. 
Neumann, M., Bensing, J., Wirtz, M., Wubker, A., Scheffer, C., Tauschel, D., Edelhauser, F., Ernstmann, N., Pfaff, H. The impact of financial incentives on physician empathy: a study from the perspective of patients with private and statutory health insurance. Patient Education and Counseling: 2011, 84(2), 208-216

\section{Figure 2}

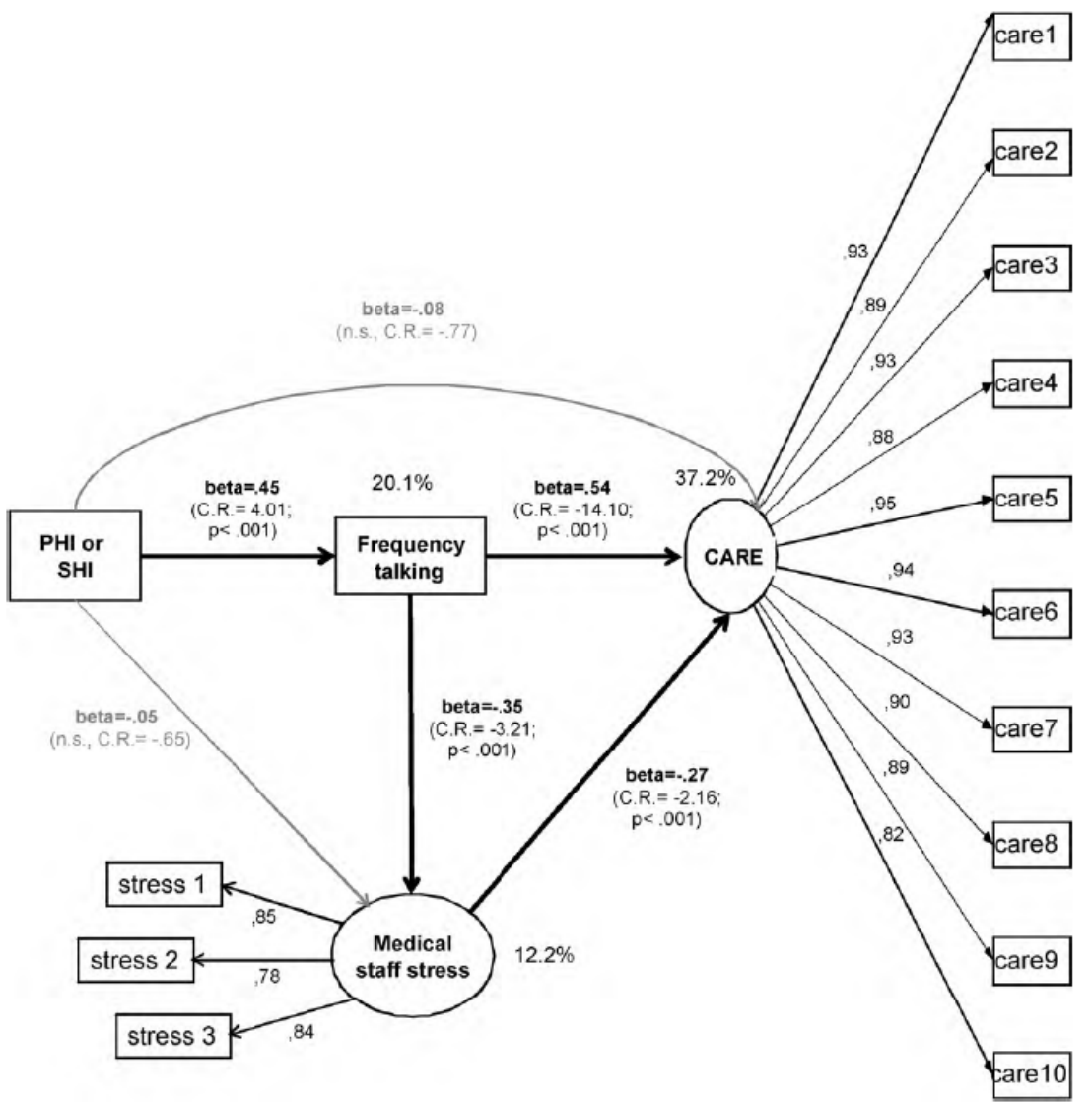

Fig. 2. Mediated path model: estimated path coefficients and percentage of explained variance for the endogenous structural constructs. Note: "PHI or SHI" = type of health insurance, i.e. private health insurance or statutory health insurance; "frequency talking" = frequency of talking with physician; CARE = Consultation-and-RelationalEmpathy measure, i.e. subjectively perceived physician empathy. 